\title{
CONDIÇÕES DE TRABALHO, CUSTO HUMANO E DANO FÍSICO: UM ESTUDO COM ESTIVADORES DE UM TERMINAL PORTUÁRIO
}

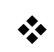 \\ Rosana Marques da Silva \\ Universidade do Vale do Itajaí - UNIVALI - Brasil \\ Maria Vitória Schizzi Tiepo \\ Universidade do Vale do Itajaí - UNIVALI - Brasil
}

\section{Resumo}

Esse estudo analisou a avaliação dos estivadores atuantes de um terminal portuário em relação as suas condições de trabalho, custo humano e dano físico, abrangendo as suas multidimensões. Pesquisa documental, de caráter descritivo - exploratório, cuja coleta de dados aconteceu por meio da aplicação do ITRA- Inventário de Trabalho e Riscos de Adoecimento. A amostra foi composta por 56 trabalhadores, que ocupam o cargo de estivador em um terminal portuário privado, localizado em Santa Catarina. Os subfatores analisados foram as condições de trabalho, custo afetivo, cognitivo e físico e dano físico, por meio de estatística descritiva. No contexto de trabalho, questões com médias maiores referem-se à existência de muito barulho no ambiente e à recorrência de riscos à segurança das pessoas. Os resultados do custo cognitivo indicaram estado crítico $(\mu=2,91)$, sendo que os itens usar a visão de forma contínua, usar a memória e ter concentração mental obtiveram médias maiores. Os resultados do custo afetivo indicaram estado satisfatório $(\mu=2,24)$, no entanto os itens ter controle das emoções, ter que lidar com ordens contraditórias e ter custo emocional apresentaram classificação crítica à saúde do trabalhador. O custo físico indicou resultados graves $(\mu=3,97)$ no que se refere a usar a visão de forma contínua, ter concentração mental e usar a memória, apontando alto potencial para o adoecimento, sugerindo relação com os danos físicos apontados pelos trabalhadores, tais como dores no corpo, dores nas costas e alterações no sono.

Palavras-Chave: Saúde do trabalhador. Psicodinâmica do trabalho. Fatores picossociais de risco.

\section{Introdução}

No Brasil o trabalho portuário constitui-se como uma das mais antigas possibilidades de inserção profissional, sendo caracterizado por atividades de embarque e armazenamento das cargas dos navios. Também, é marcado pela diversidade em função do tipo de carga a ser transportada, ocasionando inserções distintas na composição da força de trabalho necessária para sua execução (MACHIN; COUTO; ROSSI, 2009).

Entende-se que o trabalho é visto como eixo norteador na vida cotidiana das pessoas, perpassando significados socioeconômicos, culturais, históricos, afetivos e subjetivos (JACQUES, 2003). Considerando a perspectiva da psicodinâmica do trabalho, aborda-se essa 
teoria envolvendo fatores psicossociais de risco, considerados todos os aspectos do entorno do sujeito que favorecem o adoecimento e o sofrimento no trabalho.

A Psicodinâmica do Trabalho, de acordo com Mendes (2007), é uma abordagem científica desenvolvida por Dejours na década de 90, cujo foco central é o estudo da interrelação trabalho e saúde, considerando que o contexto laboral apresenta fatores que podem contribuir ou prejudicar a saúde dos trabalhadores.

Foi realizado levantamento de pesquisas que abordam o tema nas bases de dados LILACS, PEPSIC, BVS enfermagem e BVS psicologia com os descritores: trabalhador portuário, fatores psicossociais de risco, riscos psicossociais, psicodinâmica do trabalho e doenças ocupacionais. Constatou-se que os autores estudaram a percepção dos trabalhadores portuários avulsos sobre as condições de trabalho e sobre os riscos a que estão expostos, bem como a organização do processo de trabalho (ALENCAR; BIZ, 2012; SOARES, 2006; SANTOS et al, 2011).

Estudos como os de Almeida et al (2012a), Machin, Couto e Rossi (2009), Motter (2014) e Almeida et al (2012b) investigaram a prevalência de doenças musculoesqueléticas, saúde e adoecimento, representações sobre a relação trabalho-saúde e perfil de doenças ocupacionais em trabalhadores portuários. Tais achados teóricos sinalizam a relevância científica da referida pesquisa, identificando a necessidade de investigação dos fatores psicossociais de risco, considerando que o ambiente de alto risco e adverso a que os trabalhadores portuários estão expostos, favorece maiores índices de acidentes de trabalho e doenças ocupacionais e relacionadas ao trabalho.

O trabalho de estivador requer o desempenho do labor braçal e da força física, contribuindo para o adoecimento tanto de ordem psíquica, quanto fisiológica. Infelizmente, concomitante às exigências de força corporal para o desempenho das funções, há um empobrecimento intelectual, acarretando na desvalorização social desse trabalho, acentuandose a marginalização social e a vulnerabilidade frente ao capital (COSTA et al, 2015).

Para Alencar e Biz (2012), o porto é descrito pelos trabalhadores como local perigoso, com grande ocorrência de acidentes, sendo alguns fatais. Os trabalhadores atribuem esse risco à organização do processo de trabalho e às condições heterogêneas sob as quais é realizado cotidianamente. A organização do processo de trabalho está relacionada ao trabalho em turnos sem horários fixos; às flutuações da atividade, que variam de acordo com o comércio marítimo e o período de safras; ao tipo de carga a ser transportada, entre outros aspectos.

As condições de trabalho envolvem equipes constituídas para a realização das atividades; condições adversas e precárias dos navios, máquinas e equipamentos e condições 
climáticas a que estão expostos. Também é previsto, segundo Figueroa et al (2001), que o estresse no local de trabalho é o resultado de uma deficiência de adaptação entre o trabalhador e as exigências da organização ou do emprego, observando-se diversas variáveis envolvendo o contexto laboral do sujeito.

Almeida et al (2012b) destacam que no contexto portuário há exposições ergonômicas e psicossociais, como postura inadequada, trabalho intenso realizado em turnos, envolvendo atividades e movimentos repetitivos. Ainda, as atividades são executadas, de forma geral, sob pressão psicológica e com exigência de formação, aprendizagem e adaptação, e de modo acelerado, podendo determinar o surgimento de diversas patologias.

Ao avaliar a saúde dos trabalhadores portuários do setor operacional, constata-se que atuam em atividades consideradas perigosas e de alto risco à vida, seja arrumando e estivando cargas a bordo, operando veículos de transporte de passageiros e transporte de contêineres para realizar transferências entre pátio e costado ou atuando em altura para o transporte de contêineres com pesos em toneladas aos navios. Desta forma, é um ambiente onde os acidentes de trabalho estão relacionados à queda de material suspenso, podendo levar à morte e/ou acidente grave.

Ressalta-se que o ambiente de trabalho, quando oferece contingências negativas para a saúde do trabalhador, pode propiciar sintomas depressivos e de ansiedade, perda da identidade, insegurança no contexto trabalhista, familiar e social, dentre outras questões que afetam a eficácia do sujeito (TORRES et al, 2011). É importante salientar que existem fatores constitutivos do psiquismo e o trabalho caracteriza-se como um processo de reconhecimento coletivo e individual, fundamentando-se no sistema econômico capitalista no qual a sociedade está inserida. Sob esse ponto de vista, esse estudo analisou a avaliação dos estivadores atuantes de um terminal portuário em relação as suas condições de trabalho, custo humano e dano físico, abrangendo as suas multidimensões.

\section{Método}

Este estudo foi desenvolvido por meio de pesquisa documental, a qual é realizada a partir de documentos científicos autênticos, a fim de investigar e comparar fatos sociais, estabelecendo suas características (PÁRDUA, 1997 apud PIANA, 2009). Os documentos analisados foram protocolos de respostas do Inventário de Trabalho e Riscos de Adoecimento - ITRA (versão adaptada), que segundo Mendes e Ferreira $(2007$, p.11) "procura traçar um perfil dos antecedentes, medidores e efeitos do trabalho no processo de adoecimento". 
Os protocolos foram respondidos durante trabalhos de consultoria em psicologia organizacional e do trabalho, entre os meses de maio e junho de 2015, sendo que o público consistiu de trabalhadores que ocupam o cargo de estivador em um terminal portuário privado, localizado no Estado de Santa Catarina, totalizando 81 pessoas. Cabe destacar que a coleta aconteceu durante o período laboral dos funcionários, nas salas de treinamento, com grupos de até 10 pessoas, tendo duração média de 30 a 45 minutos.

A partir desta coleta, os protocolos de respostas do ITRA foram avaliados como documentos da referida pesquisa, nos meses de junho e julho de 2016. Para a escolha dos protocolos de respostas considerou-se como critérios de inclusão: estar atuando há, no mínimo, dois anos na organização e apresentar tempo de serviço no cargo por, no mínimo, um ano. A amostra foi composta por 56 trabalhadores que preencheram tais critérios, sendo exclusos 25 protocolos de respostas.

O inventário sobre Trabalho e Riscos de Adoecimento - ITRA (MENDES; FERREIRA, 2007) é proposto como instrumento que objetiva investigar o trabalho e os riscos de adoecimento por ele provocado. Entre os fatores de risco estudados, o ITRA contempla:

\footnotetext{
(...) alguns indicadores fundamentados na Psicodinâmica do Trabalho, sendo eles: organização, condições e relações profissionais de trabalho; realização profissional e liberdade de expressão; danos gerados em consequência das exigências e vivências, caracterizados como físicos e psicossociais (MENDES; FERREIRA, 2007, p. 112).
}

O ITRA foi adaptado para a realidade proposta, sendo constituído por uma escala tipo likert de cinco pontos sendo: (1) nunca, (2) às vezes, (3) raramente, (4) frequentemente e (5) sempre. Possui quatro escalas, a saber: 1- Escala de Avaliação do Contexto de Trabalho (EACT): organização do trabalho, condições de trabalho e relações socioprofissionais; 2Escala de Custo Humano no Trabalho (ECT): custos físico, afetivo e cognitivo; 3- Escala de Indicadores de Prazer e Sofrimento no Trabalho (EPST): (a) Prazer: liberdade de expressão e realização profissional e (b) Sofrimento: esgotamento profissional e falta de reconhecimento; e 4- Escala de Danos Relacionados ao Trabalho (EDRT): danos físicos, psicológicos e sociais.

Para esta pesquisa foram analisados: EACT: subfator condições de trabalho; ECT: subfatores custos afetivo, cognitivo e físico e EDRT: subfator danos físicos. Este recorte foi escolhido pelo fato das condições de trabalho do setor portuário ser apontado, pelos autores mencionados, como de alto risco à saúde do trabalhador, denotando algumas exigências afetivas, cognitivas e físicas do trabalhador, para melhor desempenho no trabalho. Os dados foram analisados por meio de estatística descritiva, considerando média e desvio padrão, bem como o cálculo do coeficiente de alpha de Cronbach, para verificação da consistência interna. 
Foram respeitados os princípios éticos da Resolução 466/12, sendo aprovado pelo Comitê de Ética em Pesquisa, cujo número do protocolo é 611.731. Ressalta-se que foi entregue a todos os participantes o Termo de Consentimento Livre e Esclarecido.

\section{Apresentação e discussão dos resultados}

\section{Caracterização da amostra}

O estudo foi realizado em um terminal portuário privado, idealizado por um empresário local no ano de 1998. As obras foram concluídas em 2007 e no mesmo ano foram iniciadas as operações com a atracação do primeiro navio no terminal.

A organização conta com um quadro de aproximadamente 1.007 colaboradores efetivos, possuindo trabalhadores de empresas terceiras, estagiários e jovens aprendizes que integram a equipe de trabalho. Apresenta um total aproximado de 833 colaboradores na área operacional e a faixa etária média do quadro varia entre 31 e 50 anos de idade sendo a maior parte da força de trabalho efetiva, do sexo masculino. Para Machin, Couto e Rossi (2009) existem dimensões socioculturais sob as atividades exercidas que implicam fortemente na dimensão de gênero. O homem não representa apenas um sujeito dotado de maior força braçal, mas um indivíduo em exercício da sua masculinidade, o que reforça essa atividade ser, historicamente, representada por homens.

A amostra foi representada por 56 trabalhadores portuários, que ocupam o cargo de estivador, sendo quatro do sexo feminino e 52 do masculino. Muitos estudos relatam o processo de inserção da mulher ao mercado de trabalho estar sendo cada vez mais intenso, participando, efetivamente, da economia brasileira. Tal fato se concretiza quando se observam as organizações, com uma representação historicamente masculina, agregar pessoas do sexo feminino às atividades. Ressalta-se que esse movimento de participação da mulher no processo econômico do país deixa de ser uma oscilação temporária e passa a ser um fenômeno social, cada vez mais aparente nos mais diversos contextos laborais (BAYLÃO; SCHETTINO, 2014).

O cargo de estivador compreende como principal função arrumar e estivar as cargas a bordo dos navios. Seu contexto de trabalho inclui exposição climática, esforço físico, rotatividade de horários (trabalho em turno), risco de queda de objeto suspenso e trabalho em espaço confinado, previsto pela Norma Regulamentadora - NR 33 (MINISTÉRIO DO TRABALHO E EMPREGO, 2006), que trata da Segurança e Saúde nos trabalhos em Espaços 
Confinados (FIDELIO; ZANDONADI, 2014). Cabe destacar que são trabalhadores assalariados, regidos pela Consolidação das Leis Trabalhistas - CLT.

Do total de respondentes 7,14\% operavam entre 12 a 24 meses na empresa. Ressaltase que $44 \%$ da amostra atuam na empresa entre 49 a 72 meses e, apenas $4 \%$ há um ou dois anos. Em relação ao tempo de serviço no cargo, 60,71\% dos trabalhadores atuam entre 13 e 24 meses e $21,41 \%$ se distribuem entre um período de 25 a 60 meses. Somente $1,78 \%$ da amostra atuam acima de 60 meses.

\section{Condições de trabalho}

A tabela 1 apresenta os resultados referentes ao Fator Condições de Trabalho, que segundo Mendes e Ferreira (2007) definem-se como a qualidade do ambiente físico, posto de trabalho, equipamentos e material disponibilizado para a realização do trabalho, composto por 10 itens, com confiabilidade de 0,89 .

Tabela 1- Condições de Trabalho.

\begin{tabular}{|c|c|c|}
\hline Itens dos fatores & $\begin{array}{l}\text { Média / Desvio } \\
\text { Padrão }\end{array}$ & Classificação \\
\hline 1- As condições de trabalho são precárias & $1,73 \pm 0,79$ & Satisfatório \\
\hline 2- O ambiente físico é desconfortável & $2,19 \pm 1,18$ & Satisfatório \\
\hline 3- Existe muito barulho no ambiente de trabalho & $3,78 \pm 1,13$ & Grave \\
\hline $\begin{array}{l}\text { 4- O mobiliário existente no local de trabalho é } \\
\text { inadequado }\end{array}$ & $2,19 \pm 1,29$ & Satisfatório \\
\hline $\begin{array}{l}\text { 5- Os instrumentos de trabalho são insuficientes } \\
\text { para realizar as tarefas }\end{array}$ & $2,05 \pm 1,21$ & Satisfatório \\
\hline $\begin{array}{l}\text { 6- O posto/estação de trabalho é inadequado para a } \\
\text { realização das tarefas }\end{array}$ & $1,82 \pm 1,04$ & Satisfatório \\
\hline $\begin{array}{l}\text { 7- Os equipamentos necessários para a realização } \\
\text { das tarefas são precários }\end{array}$ & $1,58 \pm 0,86$ & Satisfatório \\
\hline $\begin{array}{l}\text { 8- O espaço físico para realizar o trabalho é } \\
\text { inadequado }\end{array}$ & $1,96 \pm 0,91$ & Satisfatório \\
\hline $\begin{array}{l}\text { 9- As condições de trabalho oferecem riscos à } \\
\text { segurança das pessoas }\end{array}$ & $3,67 \pm 1,30$ & Crítico \\
\hline 10- O material de consumo é insuficiente & $1,87 \pm 1,09$ & Satisfatório \\
\hline
\end{tabular}

Fonte: Questionários aplicados maio a julho/2015. 
A média geral do fator Condições de Trabalho foi de 2,28, apresentando um resultado satisfatório. Observa-se que os aspectos que mais se sobressaíram estão relacionados ao barulho no ambiente de trabalho e às condições que podem oferecer risco à segurança das pessoas. Todas as demais apresentaram resultado suficiente, apontando que o Fator “Condições de Trabalho", relacionado ao contexto laboral no qual o inventário foi aplicado, não propicia um alto risco para o adoecimento do sujeito.

Almeida et al (2012b) discorrem a respeito das características do ambiente portuário em relação à segurança do trabalhador, o qual está vulnerável a quedas, atropelamento, exposição de ruídos e pressão excessiva. De acordo com isso, percebem-se os altos riscos que o trabalhador portuário está vulnerável no contexto de trabalho, apesar da média ter se mantido satisfatória.

Embora muitos destes profissionais sintam prazer durante seu fazer laboral, não se pode afirmar que tal ambiente não traga risco a saúde do trabalhador, o que pode acarretar sofrimento pessoal. Observa-se que as questões relacionadas à infraestrutura do ambiente mantiveram-se em um nível aceitável, constatando-se que o referido terminal portuário oferece um ambiente com equipamentos necessários para o desenvolvimento das atividades. No entanto, os trabalhadores possuem consciência de que o ambiente é barulhento e de alto risco à vida.

\section{Custo humano dos trabalhadores portuários}

A tabela 2 diz respeito ao Custo Afetivo da ECHT- Escala de Custo Humano do Trabalho. Esta escala indica as descrições das exigências representadas por meio do custo físico, cognitivo e afetivo em relação ao trabalho. O custo afetivo representa o consumo emocional dos trabalhadores durante o contexto laboral, ou seja, as reações afetivas, sentimentos e estados de humor. Tal escala possui 12 itens, com confiabilidade de 0,84 (MENDES; FERREIRA, 2007). 
Tabela 2- Custo afetivo.

\begin{tabular}{l|c|c}
\hline \multicolumn{1}{c|}{ Itens dos fatores } & $\begin{array}{c}\text { Média / Desvio } \\
\text { Padrão }\end{array}$ & Classificação \\
\hline 1- Ter controle das emoções & $3,58 \pm 1,29$ & Crítico \\
\hline 2- Ter que lidar com ordens contraditórias & $2,71 \pm 1,30$ & Crítico \\
\hline 3- Ter custo emocional & $2,58 \pm 1,23$ & Crítico \\
\hline 4- Ser obrigado a lidar com a agressividade dos & $2,46 \pm 1,24$ & Crítico \\
outros & $2,19 \pm 1,06$ & Satisfatório \\
\hline 5- Disfarçar os sentimentos & $1,55 \pm 0,98$ & Satisfatório \\
\hline 6- Ser obrigado a elogiar as pessoas & $1,67 \pm 1,109$ & Satisfatório \\
\hline 7- Ser obrigado a ter um bom humor & $2,01 \pm 1,48$ & Satisfatório \\
\hline 8-Ser obrigado a cuidar da aparência física & $2,48 \pm 1,58$ & Crítico \\
\hline 9- Ser bonzinho com os outros & $2,44 \pm 1,50$ & Crítico \\
\hline 11- Transgredir valores éticos & $1,80 \pm 1,25$ & Satisfatório \\
\hline 12- Ser submetido aos constrangimentos & $1,37 \pm 0,82$ & Satisfatório \\
\hline 13- Ser obrigado a sorrir & & \\
\hline
\end{tabular}

A média da ECHT é de 2,24, traduzindo nível satisfatório. Analisando os fatores, pode-se constatar que as questões mais acentuadas foram: ter controle das emoções; ter que lidar com ordens contraditórias; ter custo emocional; transgredir valores éticos; ser bonzinho com os outros e ser obrigado a lidar com a agressividade alheia. Os resultados críticos podem estar ligados às questões envolvendo hierarquia e disputa profissional. Infelizmente, diante disso, percebe-se a discrepância existente entre o trabalho real e o trabalho prescrito, pois os trabalhadores precisam assumir uma postura que seja "aceitável" no contexto de trabalho, favorecendo a desvalorização da subjetividade do sujeito.

Segundo Costa e Santos (2013, p.46), “a diferença entre trabalho prescrito e real implica a diferença entre a tarefa e a atividade. Ou seja, entre o que está planejado em termos de trabalho e o que realmente o trabalhador executa". Este fato é possibilitado pelo fruto dos constrangimentos concretos e situacionais vividos na realidade da sua atuação, indicando a necessidade de autocontrole e grau elevado para lidar com a frustração.

Como Machin, Couto e Rossi (2009) apontam, o desgaste mental gerado pela pressão de trabalhar no porto acarreta muito sofrimento emocional ao indivíduo. Essas questões 
facilitam o processo de adoecimento, pois com a degradação do equilíbrio afetivo, pode ocorrer a somatização de sintomas, ou seja, o aparecimento de patologias fisiológicas e psíquicas.

A tabela 3 corresponde ao Custo Cognitivo da ECHT. Segundo Mendes e Ferreira (2007) significa o gasto intelectual para a aprendizagem, resolução de problemas e tomada de decisão no trabalho. Esta escala é constituída por 10 itens e tem confiabilidade de 0,86.

Tabela 3- Custo cognitivo

\begin{tabular}{l|c|c}
\hline \multicolumn{1}{c|}{ Itens dos fatores } & $\begin{array}{c}\text { Média / Desvio } \\
\text { Padrão }\end{array}$ & Classificação \\
\hline 1-Desenvolver macetes & $2,26 \pm 1,18$ & Satisfatório \\
\hline 2- Ter que resolver problemas & $2,69 \pm 1,12$ & Crítico \\
\hline 3- Ser obrigado a lidar com imprevistos & $2,98 \pm 1,11$ & Crítico \\
\hline 4- Fazer previsão de acontecimentos & $2,60 \pm 1,35$ & Crítico \\
\hline 5- Usar a visão de forma contínua & $3,5 \pm 1,33$ & Crítico \\
\hline 6- Usar a memória & $3,53 \pm 1,30$ & Crítico \\
\hline 7- Ter desafios intelectuais & $2,46 \pm 1,30$ & Crítico \\
\hline 8-Fazer esforço mental & $2,6 \pm 1,38$ & Crítico \\
\hline 9- Ter concentração mental & $3,44 \pm 1,48$ & Crítico \\
\hline 10-Usar a criatividade & $3,26 \pm 1,31$ & Crítico \\
\hline Font Qustion
\end{tabular}

Fonte: Questionários aplicados maio a julho/2015.

Ao analisar os resultados da tabela 3, referente ao custo cognitivo, observa-se que a média da escala é de 2,91, denotando classificação crítica na grande maioria das questões. Em decorrência disso, aponta-se que o trabalho no porto é uma função que demanda alto custo cognitivo. As questões envolvem os processos cognitivos, ou seja, o uso contínuo da visão, memória, concentração, esforço mental e resolução de problemas, dentre outros. Segundo Dejours (1992 apud SILVA; PEREIRA; LIMAS, 2015), o trabalho repetitivo, automatizado e monótono dificulta ao trabalhador uma visão integrada do que faz, podendo gerar uma vivência de que seu trabalho não tem sentido e significado, não fazendo parte de sua subjetividade. Verifica-se que o trabalho de estivador envolve condições as quais o sujeito não está acostumado, podendo influenciar não apenas na percepção sobre o processo laboral, como também acarretar em problemáticas para a vida cotidiana, tais como dificuldades na família e nos demais contextos sociais. 
Como apontam Machin, Couto e Rossi, (2009), os trabalhadores, em razão das condições precárias que muitos portos se encontram, precisam ter mais cautela e concentração durante o turno, conformando uma visão de sofrimento bastante visível. Ainda, somam-se às características e aos riscos desse campo de trabalho - identificado pela insalubridade, ruído excessivo, presença de poeiras e gases, luminosidade deficiente-, o risco relativo à característica específica das operações. Como os autores abordam, o desgaste mental identificado está associado à pressão durante a execução de tarefas, tendo que manter o foco contínuo e a concentração, havendo, assim, índices elevados de cansaço cognitivo.

A tabela 4 corresponde ao Custo Físico que, segundo Mendes e Ferreira (2007), exibe o gasto fisiológico que o trabalhador apresenta a partir do esforço emitido no contexto de produção. É constituído por 10 itens e tem confiabilidade de 0.91 .

Tabela 4- Custo físico

\begin{tabular}{l|c|c}
\hline \multicolumn{1}{c|}{ Itens dos fatores } & $\begin{array}{c}\text { Média / Desvio } \\
\text { Padrão }\end{array}$ & Classificação \\
\hline 1-Usar a força física & $4,57 \pm 0,70$ & Grave \\
\hline 2- Usar os braços de forma contínua & $4,48 \pm 0,76$ & Grave \\
\hline 3- Ficar em posição curvada & $3,26 \pm 1,21$ & Crítico \\
\hline 4- Caminhar & $4,03 \pm 1,07$ & Grave \\
\hline 5- Ser obrigado a ficar de pé & $3,58 \pm 1,34$ & Crítico \\
\hline 6- Ter que manusear objetos pesados & $4,01 \pm 1,10$ & Grave \\
\hline 7- Fazer esforço físico & $4,28 \pm 0,90$ & Grave \\
\hline 8-Usar as pernas de forma contínua & $3,87 \pm 1,14$ & Grave \\
\hline 9- Usar as mãos de forma repetida & $4,03 \pm 1,07$ & Grave \\
\hline 10-Subir e descer escadas & $4,30 \pm 0,97$ & Grave \\
\hline
\end{tabular}

Fonte: Questionários aplicados maio a julho/2015.

Conforme os dados apontados, a média do fator Custo Físico foi de 3,97, com Alpha de Cronbath de 0,85. Observa-se que a avaliação dessa escala foi considerada de crítica a grave, demonstrando um alto custo físico à saúde do trabalhador. Decorrente a isso, percebese que se deve avaliar o ambiente físico ao qual o trabalhador é exposto, o tipo de deficiência e suas respectivas particularidades com relação ao grau de exigência física por ele imposto (HOFFMANN; TRAVERSO, ZANINI, 2014). 
Ressalta-se que as questões que mais chamaram a atenção foram as de número dois, três, seis e dez, pois indicam as posições que os trabalhadores devem manter neste cargo, gerando desgaste físico. Como cita Guimarães (2012), as características da atividade têm contribuído para elevar os casos de adoecimento, de absenteísmo e de afastamento do trabalhador, assim observando a influência que o trabalho oferece à saúde do sujeito.

Analisando as questões, percebe-se que o sistema muscular do sujeito fica afetado e comprometido, podendo acarretar o aparecimento de diversas doenças. Junto a isso, quando o sistema corpóreo fica comprometido, muitas outras questões relacionadas acabam sendo prejudicadas, como o bem-estar psicológico, as relações socioafetivas a percepção sobre o labor, a satisfação no trabalho, entre outros. Verifica-se que os estivadores apresentam alto risco de adoecimento, bem como cansaço diário na vida cotidiana.

\section{Dano físico causado pelo trabalho}

A tabela 5 refere-se ao Dano Físico, definido, de acordo com Mendes e Ferreira (2007), como dores no corpo e problemas biológicos que o contexto laboral pode propiciar ao sujeito. É composta por 12 itens, com confiabilidade de 0,88 .

Tabela 5- Dano físico

\begin{tabular}{l|c|c}
\hline \multicolumn{1}{c|}{ Itens dos fatores } & $\begin{array}{c}\text { Média / Desvio } \\
\text { Padrão }\end{array}$ & Classificação \\
\hline 1-Dores no corpo & $2,67 \pm 1,12$ & Crítico \\
\hline 2- Dores nos braços & $2,37 \pm 1,10$ & Crítico \\
\hline 3- Dor de cabeça & $1,73 \pm 0,72$ & Suportável \\
\hline 4- Distúrbio respiratório & $1,26 \pm 0,64$ & Suportável \\
\hline 5- Distúrbio digestivo & $1,41 \pm 0,80$ & Suportável \\
\hline 6- Dores nas costas & $2,42 \pm 1,12$ & Crítico \\
\hline 7- Distúrbio auditivo & $1,42 \pm 0,78$ & Suportável \\
\hline 8-Alteração de apetite & $1,73 \pm 0,99$ & Suportável \\
\hline 9- Distúrbios na visão & $1,28 \pm 0,59$ & Suportável \\
\hline 10-Alterações do sono & $2,62 \pm 1,43$ & Crítico \\
\hline 11-Dores nas pernas & $2,16 \pm 091$ & Crítico \\
\hline 12-Disturbios circulares & $1,26 \pm 0,61$ & Suportável \\
\hline Fo: Q
\end{tabular}

Fonte: Questionários aplicados maio a julho/2015. 
A média do subfator Dano Físico foi 1,86 e desvio padrão de 0,84 . Analisando a tabela 8 , observa-se que esse subfator foi qualificado como satisfatório, apesar de apresentar alguns resultados com nível crítico. As questões mais preocupantes foram 1-“Dores no corpo”; 6"Dores nas costas" e 10- "Alteração do sono". É possível relacionar os dados desta tabela aos apontados no subfator "custo físico", pois cada qual é decorrente do esforço físico e das posturas necessárias para a realização do trabalho no contexto portuário.

Muitas doenças podem se desenvolver em função desses desconfortos ocasionados durante o labor, devido à sobrecarga, exposição a movimentos repetitivos e esforços localizados. Assim, membros do corpo humano, a maioria superiores, acabam sendo lesionados (ALMEIDA et al, 2012a). Ressalta-se que as patologias relacionadas ao trabalho são configuradas como fatores de risco adicional ou contributivo ao adoecimento do indivíduo. Como cita Martins (2012), alguns dos transtornos mais registrados no Brasil, junto à Previdência Social, são os distúrbios osteomusculares, estresse, depressão, ansiedade e afecções do trato intestinal. Em meio a isso, percebe-se como é importante intervenções no âmbito do trabalho para estudar os riscos destes na vida do sujeito.

Cabe destacar a questão 10, que aborda alterações no sono, podendo estar relacionadas ao trabalho em turnos neste terminal portuário, uma vez que cada equipe alterna semanalmente o seu turno de trabalho. Neste sentido, pode-se inferir que, como há alteração no turno durante as atividades, o organismo não se acostuma com um cronograma de horários, podendo haver desequilíbrio das funções mentais, emocionais e fisiológicas. O trabalho em turnos alternados, sem uma rotina de horários pré-estabelecida, pode ser responsável por inúmeros distúrbios fisiológicos e psicossociais. Tais condições são consideradas como alguns dos aspectos mais perversos para a saúde do trabalhador, gerando uma má organização temporal do trabalho. Dessa forma, contribui para o aparecimento de sintomas imediatos e de longo prazo, podendo acarretar numa Síndrome da Má-adaptação ao Trabalho em Turnos (RÉGIS FILHO, 2002).

Considerando as escalas avaliadas - EACT, ECHT e EDRT, do total dos cinco subfatores analisados, três mantiveram-se com resultados satisfatórios e dois com resultados grave e crítico. O resultado do subfator condições do ambiente físico de trabalho manteve-se com valor satisfatório $(\mu=2,28 ; \alpha=0,78)$, não sugerindo fatores psicossociais de risco à saúde do trabalhador. $\mathrm{O}$ valor do alpha de Cronbath refere-se à fidedignidade das respostas obtidas, o qual indicou pouca dispersão em torno da média, podendo indicar determinado consenso na percepção dos trabalhadores. 
Na segunda escala - ECHT, avaliaram-se os subfatores custo afetivo $(\mu=2,24$ e $\alpha=$ $0,75)$, custo cognitivo $(\mu=2,91$ e $\alpha=0,82)$, custo físico $(\mu=3,97$ e $\alpha=0,85)$. Dessa forma, percebe-se que apenas o custo afetivo atingiu resultado satisfatório, não indicando, de forma geral, risco psicossocial à saúde do sujeito. Todavia, nos custos cognitivo e físico, os resultados foram crítico e grave, indicando que a lacuna entre trabalho prescrito e real é grande, sinalizando pouca flexibilidade do trabalhador em relação à execução de procedimentos no contexto de trabalho. Os valores do alpha de Cronbach indicaram, em todos os fatores, bom nível de consistência interna.

Pesquisa realizada com trabalhadores portuários de transporte no mesmo terminal portuário (SILVA; PEREIRA; LIMAS, 2014) indicou resultados em nível crítico a grave, na ECHT. Dessa forma, avalia-se que tais fatores representam interferência moderada a intensa, no risco de adoecimento ao sujeito.

O subfator dano físico retrata situações que envolvem atividades repetitivas, as quais podem significar nível de adoecimento para o sujeito (MENDES; FERREIRA, 2007). Para essa investigação, analisou-se apenas o fator "dano físico", cujos dados indicaram $(\mu=1,86 ; \alpha$ $=0,84)$, denotando resultado satisfatório. Existe uma relação tênue entre os fatores dano físico e custo físico, pois ambos envolvem as questões corpóreas do trabalhador, como posição do corpo, repetição da atividade, dores e distúrbio no sistema fisiológico, entre outros.

\section{Considerações finais}

Ao longo desta investigação, várias dúvidas e questões puderam ser sanadas, podendose compreender alguns fatores psicossociais de risco que circundam o processo laboral dos estivadores.

O objetivo desse estudo foi analisar a avaliação dos estivadores atuantes de um terminal portuário em relação as suas condições de trabalho, levantando as principais exigências e custos decorrentes das atividades laborais e, não obstante, os principais problemas e danos físicos causados pelo trabalho. Verificou-se que a escala ECHT foi a mais agravada e comprometida, salientando o subfator "Custo Físico", o qual obteve a média mais alta em relação aos demais. Desse modo, pode-se perceber que tal profissão compromete de uma maneira bastante significativa o corpo do sujeito, podendo provocar riscos de adoecimento, como dores na coluna, distensões musculares, problemas relacionados à sobrecarga de pesos, entre outros. 
Os resultados com médias satisfatórias, como nas escalas EACT, EDRT, ECHT - com os subfatores "Condições de Trabalho", "Custo Afetivo" e "Dano Físico"-, demonstram que os estivadores do terminal portuário não sinalizaram como preocupante as questões relacionadas ao espaço de trabalho, as condições que a organização oferece para a execução das atividades e a divisão de normas entre os funcionários. Todavia, quando o fator "Custo Afetivo" é analisado observa-se que várias perguntas foram avaliadas como grave, constatando-se que existe interferência do trabalho no campo emocional do sujeito.

Ainda, verificando os resultados da escala ECHT, o subfator "Custo Cognitivo" teve média alta, denotando classificação crítica. Considerando que o trabalho de estivador requer atenção intensa - decorrente dos deslocamentos de cargas, manuseio de materiais e dos acidentes que podem ocorrer no terminal-, os trabalhadores precisam focar de uma maneira bastante minuciosa em suas atividades. Tal fato exige concentração e atividade mental. Podese relacionar o custo cognitivo às condições de trabalho que os estivadores se submetem, pois o próprio ambiente de trabalho sujeita o estivador a um esforço maior de suas atividades cognitivas, devido às contingências contextuais.

No subfator "Condições de Trabalho", as perguntas que obtiveram resultado crítico estão envolvidas com o barulho do ambiente e a segurança que este proporciona aos funcionários. Dessa forma, percebe-se que existe uma contradição, pois os trabalhadores precisam sempre desenvolver suas responsabilidades de maneira bastante concentrada. Todavia, se há existência de muito barulho no local, eles acabam prejudicados e, consequentemente, pode-se afirmar que existe vulnerabilidade para o adoecimento.

Decorrente dos estudos realizados em literaturas entre o período de 2005 a 2016, os quais abordam pesquisas com trabalhadores, observou-se que, dentre as abordagens utilizadas para dialogar com as intervenções realizadas, a psicodinâmica do trabalho foi a que mais pode responder a dúvidas e contribuir para a fundamentação dos dados. Tal abordagem fora desenvolvida por Dejours e tem como princípio o estudo da dialética trabalho e saúde, levando em conta que os aspectos existentes no contexto de trabalho podem influenciar no processo de adoecimento do sujeito.

O ITRA, apesar de ser fundamentado na Psicodinâmica do Trabalho, apresenta algumas limitações para avaliar os resultados com profundidade, pois os aspectos subjetivos do sujeito não podem ser transcritos para o papel. Os autores do ITRA sugerem complementar as informações levantadas por meio da abordagem qualitativa, uma vez que o instrumento permite apenas avaliar os riscos relacionados às diversas dimensões do trabalho. Neste sentido, para futuros estudos nesta organização, considerando os resultados desta pesquisa, 
sugerem-se intervenções não apenas com os funcionários, mas também com os gestores da instituição. Dessa forma, respostas mais amplas e abrangentes poderão ser contempladas, entendendo os riscos que permeiam o contexto de trabalho dos funcionários e daqueles que organizam as funções laborais.

Finalizando, aponta-se que este estudo pode servir para contribuir em pesquisas relacionadas à inter-relação trabalho e saúde, bem como, tencionar os aspectos que envolvem o processo de adoecimento, em conjunto com as condições existentes no contexto laboral em que o sujeito se encontra, favorecendo outras possibilidades de estudos.

\title{
WORKING CONDITIONS, HUMAN COST AND PHYSICAL HARM: A STUDY AMONG STEVEDORES OF A PORT TERMINAL
}

\begin{abstract}
This study analyzes the psychosocial risk factors involved in the health-illness process of port workers, and how stevedores evaluate the relationship between working conditions, human cost and physical harm. This is a document-based study, using descriptive and exploratory methods, with data collection through the application of the ITRA - Inventário de Trabalho e Riscos de Adoecimento [Inventory of Work and Risks of Illness]. The sample comprised 56 stevedores working at a private port terminal in the Brazilian state of Santa Catarina. The subfactors analyzed were: working conditions, affective, cognitive and physical cost, and physical harm, through descriptive statistics. In the work context, questions with the highest average scores related to high noise levels in the workplace and recurrent risks to personal safety. The results for cognitive cost indicated a critical state $(\mu=2.91)$, while items as extended use of eyes, using the memory, and having mental concentration obtained high average scores. The results for affective cost indicated a satisfactory state $(\mu=2.24)$, while the items having to control the emotions, having to deal with contradictory orders, and emotional cost presented scores indicting that these factors were critical to the workers' health. Physical cost indicated severe results $(\mu=3.97)$, in relation to the extended use of eyes, having mental concentration, and using the memory, indicating high potential for illness, and suggesting a relationship with the physical harm indicated by the workers, such as body pains, back pain, and disturbed sleep patterns.
\end{abstract}

Keywords: Workers' health. Work psychodynamic. Psychosocial risk factors.

\section{CONDICIONES DE TRABAJO, COSTO HUMANO Y DAÑO FÍSICO: UN ESTUDIO CON ESTIBADORES DE UNA TERMINAL PORTUARIA}

\section{Resumen}

Este estudio analizo la valorización de los estibadores actuantes de una terminal portuaria con relación a sus condiciones de trabajo, costo humano y daño físico, alcanzando sus multidimensiones. La investigación es de carácter descriptiva - exploratoria, cuya colecta de datos se dio por medio de la aplicación del ITRA- Inventario del Trabajo y Riesgos de Enfermedades. La muestra fue compuesta por 56 trabajadores, que ocupan el cargo de estibador en una terminal portuaria privada, ubicada en Santa Catarina. Los sub-factores 
analizados fueron las condiciones de trabajo, costo afectivo, cognitivo y físico y daño físico, por medio de la estadística descriptiva. En el contexto de trabajo, cuestiones con medias mayores se refieren a la existencia de mucho ruido en el ambiente y la posibilidad de riesgos a la seguridad de las personas. Los resultados del costo cognitivo indicaron estado crítico $(\mu=$ $2,91)$, siendo que los ítems como: usar la vista continuamente, usar la memoria y tener concentración mental obtuvieron medias mayores. Los resultados del costo afectivo indicaron estado satisfactorio $(\mu=2,24)$, entre tanto, los ítems tener control de las emociones, tener que lidiar con órdenes contradictorias y el costo emocional presentaron clasificación crítica para la salud del trabajador. El costo físico indico resultados graves $(\mu=3,97)$ en relación a usar la vista continuamente, tener concentración mental y usar la memoria, indicaron alto potencial para enfermedades. Con relación a los daños físicos que los trabajadores presentaron se observó, dolores en el cuerpo, dolores en la espalda y alteraciones del sueño.

Palabras claves: Salud del Trabajador. Psicodinámica del trabajo; Factores psicosociales de riesgos.

\section{Referências}

ALENCAR, M. C. B; BIZ, R. A. M. Relações entre condições e organização do trabalho e os afastamentos de trabalhadores portuários de transporte. Rev. Ter. Ocup. Univ. São Paulo, v.23, n.3, p.208-15, set./dez. 2012.

ALMEIDA, M. C. V.; et al. Prevalência de doenças musculoesqueléticas entre trabalhadores portuários avulsos. Revista Latino-Am. Enfermagem, Ribeirão Preto, v.20, n.2, p. 243-250, mar./abr. 2012a.

; et al. Trabalhador portuário: perfil de doenças ocupacionais diagnosticadas em serviço de saúde ocupacional. Acta paul. enferm., São Paulo, v.25, n.2, p.270-276, 2012b. Disponível em:<. http://dx.doi.org/10.1590/s0103-21002012000200018 >. Acesso em 02 fev.2017.

BAYLÃO, A. L. S.; SCHETtinO, E. M. O. A Inserção da Mulher no Mercado de Trabalho Brasileiro, 2014. Disponível em: <http://www.aedb.br/seget/arquivos/artigos14/20320175.pdf>. Acesso em: 14 out. 2016.

COSTA, L. S.; SANTOS, M. Fatores psicossociais de risco no trabalho: lições aprendidas e novos caminhos. Ricot, Coimbra, p.39-58, jun. 2013.

COSTA, V.; et al. Saúde e Trabalho na visão de trabalhadores da estiva do Porto Ferroviário, Rio Grande do Sul, Brasil. Ciência \& Saúde Coletiva, v.20, n.4, p.1207-1216, 2015.

FIGUEROA, N. L.; et al. Um Instrumento para a Avaliação de Estressores Psicossociais no Contexto de Emprego. Psicol. Reflex. Crit., Porto Alegre, v. 14, n. 3, p.653-659, 2001. Disponível em: < http://dx.doi.org/10.1590/s0102-79722001000300021 >. Acesso em: 12 jan. 2016.

FIDELIO, B. V.; ZANDONADI, F. B. Condições de segurança entre trabalhadores de espaços confinados em unidade armazenadoras de grãos sobe a ótica da nr 33. 2014. 
Disponível em: <http://www.segurancanotrabalho.eng.br/artigos/art_03082014.pdf>. Acesso em: 23 out. 2016.

GUIMARAES, M. C. Custo Humano do Trabalho e estratégias de mediação entre trabalhadores rurais. In: MENDES, A. $\mathrm{M}$ et al (orgs). Psicodinâmica e Clínica do Trabalho: temas, interfaces e casos brasileiros. Curitiba: Juruá, 2012, p. 217 - 242.

HOFFMANN, C.; TRAVERSO, L.D.; ZANINI, R.R. Contexto de trabalho das pessoas com deficiência no serviço público federal: contribuições do inventário sobre trabalho e riscos de adoecimento. Gest. Prod., São Carlos, v.21, n.4, p.707-718, dez.2014. Disponível em: < http://dx.doi.org/10.1590/0104-530x379.> Acesso em: 20 nov.2016.

JACQUES, M.G.C. Abordagens teórico-metodológicas em saúde/doença mental \& trabalho. Psicologia \& Sociedade, Belo Horizonte, v.15, n.1, p.97-116, jan. 2003. Disponível em: <http://dx.doi.org/10.1590/s0102-71822003000100006.> Acesso em: 15 dez.2016.

MACHIN, R.; COUTO, M. T.; ROSSI, C.C.S. Representações de Trabalhadores Portuários de Santos-SP sobre a Relação Trabalho-Saúde. Saúde Soc, São Paulo, v. 18, n. 4, p.639-651, 2009.

MARTINS, S. R. Intervenções em grupo na clínica do trabalho: uma experiência anunciada em sonho. In: MENDES; A. M et al (org). Psicodinâmica e Clínica do Trabalho: temas, interfaces e casos brasileiros. Curitiba: Juruá, 2012. p.347-363.

MENDES, A. M.; FERREIRA, M. C. Inventário sobre trabalho e riscos de adoecimento ITRA: Instrumento auxiliar de diagnóstico de indicadores críticos no trabalho. In: MENDES, A. M. (Org.). Psicodinâmica do Trabalho: teoria, método e pesquisas. São Paulo: Casa do Psicólogo, 2007. p.111-126.

MENDES, A. M. Da Psicodinâmica à Psicopatogia do Trabalho. In: Psicodinâmica do Trabalho: teoria, método e pesquisas. São Paulo: Casa do Psicólogo, 2007. p. 29 - 38.

MINISTÉRIO DO TRABALHO E EMPREGO. NR-33 segurança e saúde nos trabalhos em espaços confinados Publicação D.O.U. Portaria MTE n. ${ }^{\circ}$ 202, 22 de dezembro de 2006 27/12/06. Disponível em: < http://sislex.previdencia.gov.br/paginas/63/mte/2006/202.htm>. Acesso em: 15 dez. 2016.

MOTTER; A. A. Condições de trabalho, saúde e adoecimento de estivadores do Porto de Paranaguá - PR. In: CONGRESSO NACIONAL DE SEGURANÇA E SAÚDE NO TRABALHO PORTUÁRIO E AQUAVIÁRIO, 2014, Itajaí. Anais ... Itajaí: [s.n], 2014.

PIANA, M. C. A construção do perfil do assistente social no cenário educacional: a construção da pesquisa documental: avanços e desafios na atuação do serviço social no campo educacional. São Paulo: Unesp, 2009. 233 p.

RÉGIS FILHO, G.I. Síndrome da Má-Adaptação ao Trabalho em Turnos: uma abordagem ergonômica. Produção, Florianópolis, v. 11, n. 2, p.69-87, abr. 2002. 
SANTOS, D. A; et al. Análises das condições ergonômicas dos carregadores portuários do porto de Manaus-AM. In: VII Congresso Nacional de Excelência em Gestão. 2011, Rio de Janeiro. Anais... Rio de Janeiro: [s.n], 2011, p.1-17.

SOARES, J. F. S. Saúde do trabalhador e risco no ambiente de trabalho: conhecimento dos trabalhadores portuários avulsos (TPA's) do Porto do Rio Grande -RS. 2006. 222 fls. Dissertação (Mestrado) - Programa de Pós-graduação em Enfermagem, Universidade Federal do Rio Grande, Rio Grande, 2006.

SILVA, R. M; PEREIRA, L; LIMAS, B. T. Contexto de trabalho e custo humano no trabalho: um estudo com trabalhadores portuários de transporte. Trabalho de Iniciação Científica do curso de Psicologia, 2015. Texto não publicado.

TORRES, A.R.A.; et al. O adoecimento no trabalho: Repercussões na vida do trabalhador e de sua família. Sanare, Sobral, v. 10, n. 1, p.42-48, jun. 2011.

Data de recebimento: 09/05/2017

Data de aceite: 14/06/2017

\section{Sobre as autoras:}

Rosana Marques da Silva é Docente dos cursos de Psicologia e Relações Públicas da Universidade do Vale do Itajaí - UNIVALI; Mestre em Engenharia de Produção e doutoranda em Psicologia - UFSC. Endereço Eletrônico: marques@univali.br

Maria Vitória Schizzi Tiepo é Acadêmica do $8^{\circ}$ período do curso de psicologia da Universidade do Vale do Itajaí - UNIVALI. Endereço Eletrônico: mariatiepopsico@gmail.com 